\title{
Experimental Methods of Materiality Judgment on Auditor's Experience and Performance
}

\author{
Min $\mathrm{Mao}^{1,2, a}$ \\ ${ }^{1}$ Industrial and commercial management post-doctoral flow station, Nanjing University \\ ${ }^{2}$ Accounting Department, Nanjing University of Finance and Economic, Nanjing, China \\ aynn75cat@126.com
}

Keywords: Materiality judgment; Auditor's experience; Judgment performance

\begin{abstract}
As a professional activity, audit materiality judgment can be measured by its performance, i.e. consensus, self-insight and stability. This research survey auditing materiality judgment performance in our country with the aid of experimental research method, providing simulating environment and key clues for experiment object. Research results indicate that there is not prominently difference in judgment stability and self-insight for experienced and inexperienced auditors, but experienced auditors have higher consensus than inexperienced auditors.
\end{abstract}

\section{Introduction}

Auditor's materiality judgment is expressed as certain achievement, i.e. materiality judgment performance. The materiality judgment performance can not only become the criterion of evaluating the auditing materiality judgment, but also be regarded as the basis of identifying the auditor's responsibility. In virtue of empirical experimental method, this research study auditors' materiality judgment performance by providing simulation environment and key clue.

\section{2.literature review and research hypothesis}

From 1970s, materiality judgment performance has been an important topic of abroad auditing judgment research. The abroad research mainly focus on following: Messier (1983) ${ }^{[1](P 611-618)}$ study the effect of audit experience, firm type and financial variables on materiality judgment performance, consensus, self-insight and stability; and find out that the audit experience and the firm type affect the auditors' materiality judgment consensus. Estes and Reames (1988) [2] (P291-296) point out that personnel characteristics affect the materiality decision and auditors' self-confidence. In the research, the personnel characteristics include auditors' age and experience in list company auditing; the research discover the auditors' self-confidence is positively associated with the exterior auditing experience.

It is a pity that the empirical researches were done in the background of USA. Any judgment is done under certain environment, and closely relate with the auditor's special education, culture, social and economic system. To realize the auditing materiality judgment quality under different circumstance will provide abundant conclusion and evidence for this research; it is exigent to extend the study to the China system. In China, although some scholars has realized the significance of auditing judgment, but there is still big gap comparing with abroad research. It is noticeable that Professor Zhang Jixun has done some research and got serial achievements, in the research of (2006a) [3] (P40-44) ; he studied the case of internal control risk evaluation, examine the C PA's auditing quality judgment by empirical study method, and find out the CPA's Consensus, self-sight and Stability have reached certain high level. In the subsequent study, Mr.Zhang Jixun divided the firm into 2 categories, i.e. the firm with negotiable security \& future qualification and the firm without negotiable security \& future qualification; and found out the former CPA's Consensus, self-sight is better than latter, but not prominent. Based on previous mentioned research, Mr.Zhang Jixun (2008) ${ }^{[5](\mathrm{P} 70-75)}$ regarded internal control risk evaluation as normal task and regards analysis program risk evaluation as superior task; they found out there is not prominent difference between the experienced and inexperienced auditors in stability and self-sight in normal task of internal control risk evaluation, but the consensus of experienced auditors is much better than the inexperienced auditors; in the superior task of analysis program risk evaluation, the stability and consensus of experienced auditor is much better than the inexperienced auditor, but there is no big 
gap in self-sight. The research done by Mr.Zhang is pioneer, but it is a pity there is no research on materiality judgment-a key field of audit judgment.

This research mainly studies 3 issues: A. to verify the domestic CPA's audit materiality judgment performance, to determine the status of domestic CPA's audit materiality judgment performance, to explain the progress of domestic CPA's audit materiality judgment. B. To compare the audit materiality judgment performance of the accountant from negotiable security \& future qualified firm with the accountant from no- negotiable security \& future firm.

\section{Research method}

\section{Experiment design}

This research adopts experiment research method. This method studies the cause and effect of the variables by changing the independent variable, and it is a main research method of audit materiality judgment and decision. This research use the two level fractional factorial experimental design $\left(3 \times 2^{8} \times 1 / 16\right)$. This experiment is done by providing materiality clues to CPAs; there are 8 clues (i.e. 8 factors) and 2 levels for each clue, showed in Table 1. Take a within subjects design and after combination, there are total $256\left(2^{8}\right)$ cases; to avoid the ennui of too much case, we select 16 cases randomly. For control, our experiment take a within subjects design, and the participants are audit partners, audit manager and assistant.

We calculate the Pearson correlation coefficient of each participant with other participant in the same experience team of 16 cases to judgment Consensus. To test the participant's stability, we use the method of Joyce (1976) ${ }^{[5](\mathrm{P} 29-60)}$. We select 4 cases from 16 experimental cases randomly, and retest the 4 cases in random sequence; the Pearson correlation coefficient of 2 time tests of each participant in the re-tested 4 cases is stability. To test the participants' self-insight, they are requested to grade the weight of each clues of each task so that we can measure the participant' recognition degree of each clue during the judgment. The recognition degree of each clues they used during the judgment process is regarded as the objective weight of each cue.

Table 1. 8 Main Clues for Experiment

\begin{tabular}{|c|c|c|}
\hline \multirow[t]{2}{*}{ Clues } & \multicolumn{2}{|l|}{ Status of clues } \\
\hline & Strong & Weak \\
\hline $\begin{array}{l}\text { 1.The development tendency of } \\
\text { the audited unit. }\end{array}$ & $\begin{array}{l}\text { diversified and expansionary } \\
\text { industry }\end{array}$ & single and shrinking industry \\
\hline 2.Structure of the audited unit & $\begin{array}{l}\text { List company, the main users } \\
\text { of the financial statement are } \\
\text { shareholders. }\end{array}$ & $\begin{array}{l}\text { Private - no list company, the } \\
\text { main users of the financial } \\
\text { statement are creditors. }\end{array}$ \\
\hline $\begin{array}{l}\text { 3. The accounting policy tendency } \\
\text { of the audited unit }\end{array}$ & Conservative & Aggressive \\
\hline $\begin{array}{l}\text { 4.The internal control of the } \\
\text { audited unit }\end{array}$ & Complete & Incomplete \\
\hline $\begin{array}{l}\text { 5.The influence of adjusted items } \\
\text { on asset- liability ration of the } \\
\text { audited unit(The industry's asset } \\
\text { liability ratio is generally between } \\
50 \% \sim 70 \% \text { ). }\end{array}$ & $\begin{array}{l}\text { Asset- liability ration rise } \\
\text { from } 50 \% \text { to } 60 \%\end{array}$ & $\begin{array}{l}\text { Asset- liability ration rise from } \\
70 \% \text { to } 80 \%\end{array}$ \\
\hline $\begin{array}{l}\text { 6. The influence of adjusted items } \\
\text { on net profit of the audited unit. }\end{array}$ & Net profit decreased by $2.7 \%$ & Net profit decreased by $7.3 \%$ \\
\hline $\begin{array}{l}\text { 7.The influence of adjusted items } \\
\text { on net asset of the audited unit. }\end{array}$ & Net asset decreased by $2.1 \%$ & Net asset decreased by $6.3 \%$ \\
\hline $\begin{array}{l}\text { 8.The influence of adjusted items } \\
\text { on earnings per share tendency. }\end{array}$ & $\begin{array}{l}\text { No change in the past three } \\
\text { years of earnings per share } \\
\text { increased upward trend. }\end{array}$ & $\begin{array}{l}\text { Changed the rising earnings } \\
\text { per share tendency of last } 3 \\
\text { years. }\end{array}$ \\
\hline
\end{tabular}

These 8 clues are divided into 2 category by conception, the former 4 are the most representative clues which affect the materiality judgment and were suggested in literatures, such as Firth(1979) ${ }^{[5](\text { (283-295) }}$, Messier(1983). The latter 4 are recognized financial clues which affect the 
materiality decision the most closely.

\section{Experiment task}

Based on Krogstad et al. ${ }^{[10](\text { P54-73) }}$ case and integrated with Domestic situation, this research provide 8 clues of audit materiality. The participants are requested to assume that they are the directors of the accounting firm and to judge the materiality of less allowance for bad-debt provision. Audited accounts receivable less provision for bad debts amount according to the provided clues. Based on this, the participants are requested to judge the audit report type if the audited unit don't accept the related adjusting entries.

This experiment chose the task based on three considerations: 1. It is a routine Routine business of financial statements audit to evaluate the accrued ratio rate of account receivable provision for bad debts; 2. In financial statement, account receivable is the key business. After the test, the participants are requested to give and score the relatively materiality level of the 8 clues and the total score is 100 , the ratio to the total score is the participant's judgment weight.

\section{Participant and test process}

The participants are CPAs from national and regional accounting firm; total 129 people. Among them, 79 people are from the accounting firm related to security \& future business and the other 50 people are from other accounting firm, and the average audit experience is 4 years.

The procedure is: 1.Distribute the research purpose, detailed instruction and sample case to each participant; 2. Request each participant to judge the case. Ensuring each participant, especially assistant has enough time to understand the process; 3 . Distribute the 32 audit study cases (16 repetitions) to each participant randomly and collect them back after the accomplishment.

\section{Data analysis and test result \\ Consensus}

As mentioned before, the indexes for measuring the audit materiality judgment performance are Consensus, stability and self-insight. We analyze these 3 indexes according to the experimental data, and analyze further if there is significant difference between the security \& future qualified accounting firm and other accounting firms in materiality judgment performance.

Table 2. Statistics of Consensus

\begin{tabular}{|l|l|l|l|l|c|}
\hline & $\mathrm{N}$ & Minimum & Maximum & Mean & Std. Deviation \\
\hline $\mathrm{X}$ & 129 & -0.23 & 0.75 & 0.61 & 0.14 \\
\hline Valid N (listwise) & 129 & & & & \\
\hline
\end{tabular}

Consensus is the conformity of different CPA's judgments with the same information at the same time. We calculate average Pearson correlation coefficient of each CPA's judgment to others, and using it to measure the consensus, if the average value is high, the Consensus is high. The statistics of Consensus is shown in Table 2.

Table 3. Test result of Single sample T Consensus

\begin{tabular}{|l|l|l|c|c|c|c|}
\hline \multicolumn{5}{|l|}{ Test Value $=0.76$} \\
\hline \multirow{2}{*}{$\mathrm{t}$} & $\mathrm{df}$ & Sig.(2-tailed) & Mean difference & \multicolumn{2}{|c|}{$95 \%$ Confidence Interval of the Difference } \\
\cline { 5 - 6 } & & & & Lower & Upper \\
\hline-5.34 & 128 & 0.000 & -0.28 & -0.36 & -0.19 \\
\hline
\end{tabular}

It shows in Table 2, the average Consensus of the participants is 0.61 , the minimum is -0.23 , the maximum is 0.75 and the standard deviation is 0.14 ; it means the Consensus is quite high, but still lower than Messier' result of 0.76、Krogstad et al's result of 0.72 . The test result of single Sample $\mathrm{T}$ indicate the gap between the average Consensus and Messier's average Consensus is -0.15 , the gap is remarkable ( $p<0.05$ ), it shows the average Consensus of Domestic CPA is lower than the CPA in U.S.A. After further analysis, we find out the Consensus of a substantial portion CPA is lower than 0.6 , the portion is $24 \%$ and there is even a negative correlation; in Messier's test, the portion which is lower than 0.6 is only $3 \%$; the Consensus of a substantial portion Domestic CPA is relatively low compared with the CPA in U.S.A.and this is the reason of low average Consensus.

In Table 4, for no-qualified group, the average Consensus of materiality judgment is 0.6553 ; 
for qualified group, it is 0.6871 . The audit judgment performance of qualified group is a little higher than the no-qualified group, but the difference is not notable $(p>0.05)$. In addition, the standard deviation of the no-qualified group is bigger than the qualified group, it explains the low and fluctuant Consensus of the no-qualified group.

Table 4. Consensus of 2 independent sample

\begin{tabular}{|c|c|c|c|c|c|c|c|c|c|}
\hline & & Minimum & Maximum & Mean & Medium & $\begin{array}{l}\text { Std. } \\
\text { Deviation }\end{array}$ & $\begin{array}{l}\text { Mean } \\
\text { difference }\end{array}$ & $\mathrm{t}$ & $\mathrm{p}$ \\
\hline $\begin{array}{l}\text { No-qualified } \\
\text { group }\end{array}$ & 0 & 0.11 & 0.78 & 0.6553 & 0.6936 & 0.1225 & \multirow[t]{2}{*}{-0.0318} & \multirow[t]{2}{*}{-0.762} & \multirow[t]{2}{*}{0.431} \\
\hline $\begin{array}{l}\text { Qualified } \\
\text { group }\end{array}$ & 9 & 0.36 & 0.78 & 0.6871 & 0.7132 & 0.0783 & & & \\
\hline
\end{tabular}

Stability

Stability is the conformity CPA's judgments on the same question at different time. To measure the stability, we select 4 cases according to the $1 / 2$ part analysis for 16 cases chosen for the experiment and put them behind the 16 cases, according to the participant's answer, we calculate the Pearson correlation coefficient of the 4 cases, this coefficient is the stability. The coefficient is higher the more stable. Table 5 shows the stability statistics.

Table 5. Statistics of Stability

\begin{tabular}{|l|l|l|l|l|l|}
\hline & $\mathrm{N}$ & Minimum & Maximum & Mean & Std. Deviation \\
\hline $\mathrm{X}$ & 129 & -0.79 & 1.00 & 0.64 & 0.46 \\
\hline Valid N (listwise) & 129 & & & & \\
\hline
\end{tabular}

It shows in Table 5, the average Pearson correlation coefficient of materiality judgment of the participant is 0.64 , it is lower than 0.90 of Messier' study and 0.89 of Krogstad et al.'s study result. In table 6 , the test result of single sample $T$ shows the average Consensus (stability) gap between this research and Krogstad et al's is -0.25 , the difference is prominent $(p<0.05)$; it indicates the average stability of materiality judgment of CPA of China is much lower than CPA of USA. In Messier's research, only 6\% (4) participant's stability is lower than 0.70 ; but in China, the individual difference of the participant is bigger, the Minimum is -0.79 and the Maximum is 1 . The proportion of Pearson correlation coefficient $\mathrm{X}: \mathrm{X} \leq 0,23.3 \%, 0.50<\mathrm{X}<0.67,20.4 \%, \mathrm{X}<0.7,42.5 \%$; it indicate almost half of participant's stability is low. Comparing with the Consensus, Stability is lower than Consensus; it shows the judgment Conformity of the same CPA at two different times is smaller than the Conformity of different CPAs at the same time.

Table 6. Test result of Single sample T Stability

\begin{tabular}{|c|c|c|c|c|c|}
\hline \multicolumn{6}{|c|}{ Test Value $=0.89$} \\
\hline \multirow[t]{2}{*}{$\mathrm{t}$} & \multirow[t]{2}{*}{$\mathrm{df}$} & \multirow[t]{2}{*}{ Sig.(2-tailed) } & \multirow[t]{2}{*}{ Mean difference } & \multicolumn{2}{|c|}{$95 \%$ Confidence Interval of the Difference } \\
\hline & & & & Lower & Upper \\
\hline-5.349 & 128 & 0.000 & -0.25 & -0.35 & -0.18 \\
\hline
\end{tabular}

It shows in Table 7, the average materiality judgment stability of no-qualified group is 0.558 ; and it is 0.513 for qualified group and is lower than the stability of no-qualified group; but the difference is not big. For no-qualified group, the minimum is -0.63 , the maximum is 1 , the Medium is 0.728 , Standard Deviation is 0.47 . For qualified group, the minimum is -0.81 , the maximum is 1 , the Medium is 0.563 , Standard Deviation is 0.438. On the contrary, from the above data, the stability of no-qualified group is higher than qualified group.

Table 7. Results of two independent samples T test stability

\begin{tabular}{|l|l|l|l|l|l|l|l|l|l|}
\hline & & Minimum & Maximum & Mean & Medium & Std.Deviation & $\begin{array}{l}\text { Mean } \\
\text { difference }\end{array}$ & $\mathrm{t}$ & $\mathrm{p}$ \\
\cline { 1 - 1 } & 0 & -0.63 & 1 & 0.558 & 0.728 & 0.47 & 0.045 & 0.618 & 0.536 \\
No-qualified & & & & & & & \\
\hline Qualified group & 9 & -0.81 & 1 & 0.513 & 0.563 & 0.438 & & \\
\hline
\end{tabular}

\section{Self-insight}

Table 8. Statistics of Self-insight

\begin{tabular}{|l|l|l|l|l|l|}
\hline & $\mathrm{N}$ & Minimum & Maximum & Mean & Std. Deviation \\
\hline $\mathrm{X}$ & 129 & -0.89 & 1.00 & 0.58 & 0.46 \\
\hline
\end{tabular}


It shows in Table 8 , the mean value of the participant's Self-insight is 0.58 , it is lower than Messier's experimental result of 0.83 and Krogstad et al's experimental result of 0.77 . Figure 9 is the Results of self-insight of single sample T test, it shows the difference with Messier's result 0.83 is -0.25 , and the difference is prominent $(p<0.05)$. It indicates the Self-insight of the participant is lower than the self-insight of CPA USA prominently. At the same time, it means, as a whole, the familiarity of the judgment policy of Domestic CPA is relatively low, but there are still considerable quantities of CPA reaching high level of Self-insight. For example, the portion above 0.76 is $42 \%$ and the portion above 0.88 is $24 \%$. At the same time the individual difference for the Self-sight is big, the maximum is 1 and the minimum is -0.89 and the Standard deviation is 0.46 . It shows some CPA completely misread their judgment policy (the portion of -0.89 is $15 \%$ ), and some CPA understand the judgment policy perfectly. This is the reason for low population mean value of Self-insight. The data in Table 9 shows Stability has significant correlation with Self-insight, the coefficient of correlation is $0.281(p<0.01)$, it show the higher Self-insight, the more understanding of the judgment policy and the higher stability. So the low stability is connected with low Self-insight.

Table9. Self-insight results single of sample T test

\begin{tabular}{|l|l|l|c|c|c|c|}
\hline \multicolumn{5}{|c|}{ Test Value $=0.83$} \\
\hline \multirow{2}{*}{} & $\mathrm{t}$ & $\mathrm{df}$ & Sig.(2-tailed) & Mean difference & \multicolumn{2}{|c|}{$95 \%$ Confidence Interval of the Difference } \\
\cline { 5 - 6 } & & & & Lower & Upper \\
\hline & & & & -0.25 & -0.12 \\
\hline
\end{tabular}

\section{Main conclusion}

The Consensus, Stability and Self-insight of CPA China have reached certain high level. In other words, the audit materiality performance of CPA China has reached certain high level, this is related to the training, practice and guidance of CICPA and the audit firm and effective coaching of audit standard.

Next, the Standard deviation of the Stability and Self-insight for CPA China is relatively large. A substantial portion of CPA China has relatively high audit materiality performance, but a substantial portion of CPA China has relatively low audit materiality performance at the same time. It may be because of relatively big personnel difference of CPA China.

The stability of CPA China is lower than Consensus; it means the consistency of the judgment for the same CPA at different time is lower than that for different CPA at the same time.

Comparing with abroad similar study, the gap is obvious, the gap of Stability and Self-insight is relatively big, it may relate with the CPA's short audit history in China, professional immaturity and low overall quality.

Consensus, stability and self-insight of the accountant from security \& future qualified accounting firm is slightly higher than that of the account from the security \& future no-qualified accounting firm, but it is not prominent. In other words, the market admittance system of China listed company audit didn't improve the audit materiality judgment performance significantly.

\section{References}

[1]Messier, W. F., Jr: The effect of experience and firm type of materiality / disclosure judgments. Journal of Accounting Research Vol.21, (1983), p611-618.

[2]Estes, R., and D. Reames: Effects of personal characteristics on materiality decisions: A multivariate analysis. Accounting \& Business Research, Vol.18 (1988), p291-296.

[3]Jixun Zhang, Chenli Liu and Mingzeng Liu: Qualification and audit judgment quality: An experimental study. Auditing Research, Vol.5 (2006), p40-44.

[4]Jixun Zhang, Chenli Liu and Mingzeng Liu: Experimental study Chinese audit judgment quality. Nankai Business Review, Vol.9(2006), p45-49.

[5]Jixun Zhang, Honglin Fu: Experience, the nature of the task and the quality of audit judgment. Auditing Research, Vol.3(2008), p70-75.

[6]Joyce, E. J: Expert Judgment in Audit Program Planning. Journal of Accounting Research, 
Vol.14(1976),p29-60.

[7]Firth, M: Consensus Views and Judgment Models in Materiality Decisions.Accounting, Organizations and Society, Vol.14(1979),p283-395.

[8]Moriarity, S. \& Barron, F. H: Modelling the Materiality Judgments of Audit Partners. Journal of Accounting Research, Vol.3(1978), p320-341.

[9] Holstrum, G. L. \& Messier, W. F: A review and integration of empirical research on materiality . Auditing: A Journal of Practice and Theory, Vol.3(1982), p45-63.

[10] Krogstad et al: Context and Experience in Auditors' Materiality Judgments. Auditing: A Journal of Practice and Theory, Vol. 4(1984),p54 -73. 